\title{
Trans Ecologies of Resistance in Digital (after)Lives: micha cárdenas' Sin Sol/No Sun
}

\author{
GIULIA CASALINI \\ PhD candidate, Roehampton University
}

\section{ABSTRACT}

This essay analyzes micha cárdenas's Sin Sol/No Sun, an augmented reality game that calls attention to gendered and racialized violence, environmental destruction, and colonial violence. It surveys the role that feminist, trans, and queer artists and theorists have occupied in the domain of digital technologies and how utopian post-identitarian approaches within cyberculture led to digital materialist perspectives, thus recentering their discourses on the relationship between the body and the hardware. From there, it explores how cárdenas's "transreal aesthetics," informed by trans embodiments and Black feminist practice, draws attention to multi-dimensional ecologies (virtual and physical) while raising pressing issues around marginalized identities and the environment. The essay concludes with an analysis of how cárdenas's avatars guide players through processes of collective grief in order to unmake the space-time categories imposed by Western colonial capitalism and speculate (or "afro-fabulate") the possibilities of new worlds.

I- / am here, / to tell you / how the sky died, / how those who travelled across borders and / built homes here / could only run to the ocean, / for fear of the cops at the shelters, / how I coded my own body and soul, and / how I escaped the / bright orange wall of raging eyes of flame, that / turned the sky black and took away the sun, and the moon. / it- / it- / it. / is so good to see you, / to know my words made it through time / to reach another heart, unthawed / still a smoldering ember.

The large, mechanized flower opens up as I approach, releasing a light blue mist and the figure of Aura - a woman with dark brown skin, purple wavy hair, and a light blue dress. She performs a delicate dance, leaning towards the ground and then pointing towards the sky with her left arm. [Figure 1] Cubic pixel formations appear around her body, giving the impression that a glitch might have caused her arrival. There is sadness in her expression, but also the determination of a superhero femme of color. Her eyes shine with a light blue glare as they welcome me into her world of despair and hope - a world that is so close to the present in which I live. Not far from where Aura and I stand, a robin lands on a bench, chirping, unaware of our encounter.

As players, we access the augmented reality of Sin Sol/No Sun by looking through an iPad or iPhone screen while walking in an outdoor space (preferably a park, far from obstacles) or in the 
venue that is hosting the work. The game, which premiered in October 2018 and was released to the public as an app in August 2020, is centered on the experience of how climate change disproportionately affects migrants, trans, undocumented, disabled, and chronically ill people. ${ }^{1}$ This work has been designed by micha cárdenas in collaboration with Marcelo Viana Neto, Morgan Thomas, Adrian Phillips, Abraham Avnisan, Dorothy Santos, and Wynne Greenwood. cárdenas (who writes her name without capitalization) is a first-generation Colombian American artist and Assistant Professor in Art \& Design: Games + Playable Media at the University of California, Santa Cruz, where she directs the Critical Realities Studio that developed the game. ${ }^{2}$

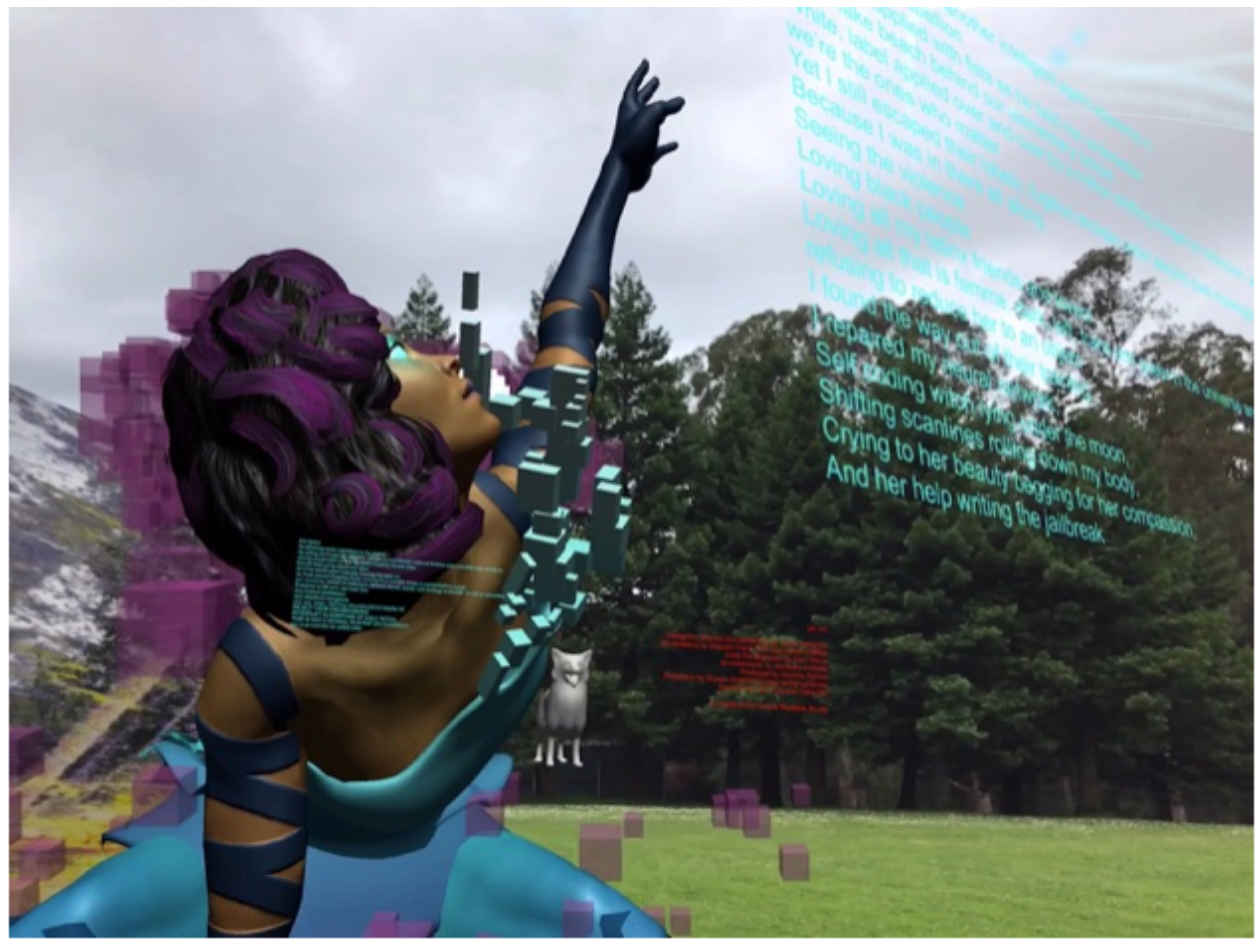

\section{Figure 1. Sin sol/No Sun, 2020, micha cárdenas, augmented reality game (C) micha cárdenas / Critical Realities Studio.}

Set 50 years in the future, Sin Sol/No Sun offers the players a series of poetic texts, which float mid-air next to flower-like "oxygen capsules." The poems are recited by Aura, the AI hologram of a trans Latina who tells us her chronicle of resistance and digital survival through dance and poetry. The game's digital landscapes overlap with the physical space of the players, who are guided by the avatar of a dog called Roja-Aura's dog. Set in the aftermath of an environmental apocalypse caused by climate change-induced wildfires, Aura's narrative is accompanied by a melancholic electronic music soundtrack that becomes increasingly dramatic as we move through the work.

In the months following the release of the game, regions across the globe (from Siberia to Australia) were consumed by incessant wildfires and, since 2015, seven of the ten most destructive wildfires in the world have occurred in California, where the artist lives. ${ }^{3}$ As a way to 
archive those ecosystems that continue to be severely affected by climate catastrophes, the game's digital landscapes have been carved out of 3D scans from present-day local forests. In this sense, our lived present is virtually designed within the history of devastation that Aura narrates in the game.

In the sections that follow I will navigate how, despite persisting discriminations, traditionally marginalized subjects have found their means for self-empowerment through the use of digital technologies. ${ }^{4}$ I will then position cárdenas's Sin Sol/No Sun within a digital materialist perspective that is indebted to the discourses and practices of cyberfeminism and, more specifically, to transgender approaches in relation to technology and the virtual. In conclusion I will observe how racialized avatars like Aura produce the conditions for thinking through acts of world-making that are radically anti-colonial and anti-extractivist.

\section{Cyberfeminism's Digital Materialism}

In recent years, ecological awareness has grown exponentially, and protests such as those of Standing Rock and Extinction Rebellion have highlighted the urgency of climate and environmental action with creative and disruptive strategies. ${ }^{5}$ The global growth and consumption of digital technologies has also revealed its environmental and socio-economic impacts on a large scale: the mass dumping of e-waste from the Global North to Africa; ${ }^{6}$ the exploitation of mineworkers for the production of digital devices $;^{7}$ the growing level of the carbon footprint produced by data storage centers $;^{8}$ the built-in racism of facial recognition technology ${ }^{9}$ or the "digital colonialism" of US Big Tech corporations in the Global South, together with its new forms of imperialistic control and surveillance. ${ }^{10}$

Ecologically conscious reflections have therefore also entered the digital arts sector, with traditionally marginalized artists stressing the materialist aspects of the virtual and producing works that counteract privilege, exclusions, and violence across virtual and "real" environments. ${ }^{11}$ The 2017 Post-Cyber Feminist International symposium, hosted at the Institute of Contemporary Art in London, represented these positions: the event, which marked the 20th anniversary of the First Cyberfeminist International, included some of the original members, such as Cornelia Sollfrank and Shu Lea Cheang, who discussed their current practice together with younger artists and activists in the field of digital technologies. ${ }^{12}$ A crucial line of thought and action that emerged, especially from Black delegates, was the formulation of an embodied and re-politicized cyberfeminism — one that would consider the importance of offline presence for feminist organizing, that would promote the Away From Keyboard (AFK) time for self-care, and resignify our physical bodies as technological apparatuses of pleasure and resistance. ${ }^{13}$

The international feminist art movement known as "cyberfeminism" emerged in the early 1990s to theorize, exploit and critique the use of the internet and new media technologies. Donna Haraway's notion of "cyborg" and the depiction of a woman-machine connection strongly influenced this movement. ${ }^{14}$ Haraway's 1985 "A Cyborg Manifesto" revealed a utopian attitude, critical of identity constructs and essentialisms, which also characterized the "third-wave" feminism. ${ }^{15}$ In understanding gender, race, and class consciousness as "an achievement forced on us by the terrible historical experience of the contradictory social realities of patriarchy, colonialism, and capitalism," the author used the image of the cyborg - a human-machine 
hybrid - to imagine a world not constructed upon Western masculinist historical parameters. ${ }^{16}$ She depicted a post-gender world, where coalitions would spark by affinity rather than identity:

Identities seem contradictory, partial, and strategic. With the hard-won recognition of their social and historical constitution, gender, race, and class cannot provide the basis for belief in "essential" unity. There is nothing about being "female" that naturally binds women. ${ }^{17}$

Cyberfeminism saw the contemporary cyber-technological advancement as the ideal terrain in which to operate against the patriarchal logic and canons. ${ }^{18}$ The Australian collective VNS Matrix stated, in a manifesto that became one the movement's flagships: "We are the virus of the new world disorder / rupturing the symbolic from within / saboteurs of big daddy mainframe... we are the future cunt." 19 However, as the words of Julianne Pierce (a member of the collective) testify, the movement was relying predominantly on a disembodied use of early internet technologies:

Cyberfeminism was about ideas, irony, appropriation and hands-on skilling up in the data terrain. It combined a utopic vision of corrupting patriarchy with an unbounded enthusiasm for the new tools of technology. It embraced gender and identity politics, allowing fluid and non-gendered identities to flourish through the digital medium. The post-corporeal female would be an online frontier woman, creating our own virtual worlds and colonising the amorphous world of cyberspace. ${ }^{20}$

The post-identitarian perspectives of 1990s cybercultures found resonance in the predominantly textual quality of Web 1.0. The written communication that the early internet offered allowed users to formulate always-new identities, freed from their day-to-day bodily representations. For instance, chat rooms had no option for image upload, and the use of pixelated avatars encouraged users to represent themselves with unusual features, often disassociated from their human attributes. Anonymity was an empowering tool for sexual minorities and gender-questioning individuals who would find freedom of expression while being safe from exposure.

Nevertheless, the utopian approach to identity politics was soon exposed and criticized within feminist and queer cyber movements. For instance, in the mid-90s Donald Morton asserted that cyberspace was the terrain in which the queer escapist desire manifested a contemporary post-gay and post-lesbian attitude: "cyberqueer," in his opinion, moved away from historical materialism to engage with a "theoretically updated form of idealism." ${ }^{21}$ Morton hence condemned the queer use of cyberspace as "symptomatic of the (post)modern displacement of need by desire (the material by the ideal).,"22 Likewise, feminist scholar Nina Wakeford returned to the word "cyberqueer" to define it as an "act of resistance" in the face of suppressing sexuality in critical cultural studies of technology. ${ }^{23}$ Wakeford recognized the role of Haraway's formulations for cyberqueer discourses, although she criticized the "visionary metaphor" of the cyborg for "proving problematic when applied to user experiences." 24 To exemplify this, the author pointed out how prejudices and harassment based on identity constructs were still part of users' experiences in lesbian platforms or how issues of access or English literacy perpetuated exclusions among the same cyberqueer community. ${ }^{25}$ Wakeford thus used a materialist analytical framework to reposition bodies and identities at the center of cyberqueer discourses: while moving away from the centrality of the screen, she proposed to re-focus on "what happens to the 'real' body when the computer is on," or off. ${ }^{26}$ 
As the more interactive and image-based interfaces of Web 2.0 in the 2000s began to supplant the text-based version of the early internet, new materialist thinking reframed the utopian perspective that in cyberspace subjects could free themselves of their "real" identities. In shifting the attention away from the screen and back to the body and the hardware, feminist and media studies scholars started to dissect the material conditions surrounding the use of digital technologies, which early queer and feminist cybercultures had left largely unquestioned. Digital media theorist Lisa Nakamura accordingly pointed out how scholars have glorified the early internet for its "interactivity, gift economy, and decentralized structure" in connection to the ethos of the liberation movements of the $60 \mathrm{~s} .{ }^{27}$ However, she also criticized this approach for perpetuating discourses of "color blindness in terms of access, user experience, and content." 28

Along these lines, the same cyberfeminists post-2000s started advocating for an "embodied and politically engaged cyberfeminism" and criticized their own movement for its lack of political positioning. ${ }^{29}$ Cyberfeminist discourses thus resonated with new materialist approaches and, more specifically, with what has been conceptualized as "digital materialism." The editors of the first issue of the journal Digital Culture \& Society describe the need for digital materialism to "address the materiality of allegedly immaterial research objects such as software," which include the social, economic and ecological implications of digital technologies, and their position of non-neutrality in relation to globalized economies and politics. ${ }^{30}$ Digital materialism has been calling attention to "neglected materialities" by shedding light "on the interplay between nonhuman and human actors involved in media production and consumption dynamics." 31 The new materialist inheritance of digital materialism has offered critical ecological perspectives to engage with the urgent political, economic, and socio-cultural implications of producing, using, and disposing of digital technologies. ${ }^{32}$

A cyberfeminist praxis that is grounded in digital materialist thinking also recognizes that technological advancement has not effaced sexism, racism, or other forms of oppression, and that the virtual has material effects. From this perspective, the work of micha cárdenas makes use of the virtual as a critical space for the racialized and gendered body to reclaim and find empowerment from. ${ }^{33}$ More specifically, her work can be inscribed in a digital materialist cyberfeminist approach that is situated in trans of color knowledge and experience. ${ }^{34}$ In the next section I will explore the specificity and materiality of a transgender positioning in the field of digital technologies, from its historical legacies to cárdenas's contemporary theorizations.

\section{Trans/gender Virtual Embodiments}

Sandy Stone's foundational 1987 text within transgender studies, “The 'Empire' Strikes Back: A Posttranssexual Manifesto" is strongly influenced in its vocabulary and innovative theorization of gender and technology by Donna Haraway, who was Stone's doctoral advisor at the time. As stated previously, "A Cyborg Manifesto" was foundational for the early queer and feminist cybercultures and their post-identity politics. However, her work consisted of a less acknowledged socialist materialist framework that counteracted the neoliberal ideals of technological determinism by stressing the role that gender and race played in technological advancement. ${ }^{35}$ For instance, the author investigated the exploitative working conditions of Black and Asian women in the field of technoscience or the feminization of workers in the electronics assembly lines. ${ }^{36}$ A digital materialist perspective was then already part of Haraway's analysis of 
the "women in the integrated circuit" - an image that referred to the situation of women in a world that was "intimately restructured through the social relations of science and technology."

Using a similar lens, Stone depicted the trans body as "a hotly contested site of cultural inscription" that was socially programmed to disappear: a body whose complexities and ambiguities have been erased by having to fit within a Western binary logic. ${ }^{38}$ For Stone, the only way that the "transexual" subject could find a way to speak, was to become "posttranssexual" by overcoming the necessity of "passing" or being "read" as either male/female, and producing instead a myriad of identities that would exceed the traditional frames of representation. ${ }^{39}$ With the plea to "write oneself into the discourses by which one has been written" ${ }^{\text {" St }}$ Stone also gestured to the hacker's operation of "breaking the code" - a practice she was actively engaged in since the 1950s. ${ }^{41}$ In her later book The War of Desire and Technology at the Close of the Mechanical Age (1995) Stone then pointed to the "dawn of the virtual age" as the space in which trans subjectivities could dwell and continue their processes of transformation. In this text, she theorized how the transgender body was "natural" to cyberspace and "unnatural" to the physical world due to the social projections that the latter subjected it to. ${ }^{42}$

In announcing that the "natural" place for the transgender body was the virtual, Sandy Stone also positioned her observations within a transgender experience of body hacking. Practices of gender transition involve changing one's name, finding and administering self-medication (e.g., on or under the counter hormones), using prosthetic devices (e.g., silicone breasts, chest binding), or surgeries to hack one's own body and identity with or without medical or psychological approval. The application of DIY technology on one's body has therefore been a crucial tool for trans survival and resistance. While the concepts of "natural" and "unnatural" in Stone relate to an idea of "nature" that is socially and medically constructed, it is through technology itself that a trans subjectivity can thrive and find its own ecology. Ecology could be considered the study of the home or of the place we live in - the term coming from the Greek oikos, which means house, household, dwelling place, or family; and logos, which means word, language, or the language of reason. ${ }^{43}$ Stone's position hence suggests that

trans is "at home" with the virtual, as its environment offers the trans body a ground in which its existence is "natural" beyond the parameters in which "nature" has been constructed within the physical, heterosexist, and gender-binary world.

Two decades after Stone's foundational intervention, micha cárdenas stresses the digital ecology of the trans subject through the concept of "transreal," which bridges the virtual and physical dimensions of the "real" through aesthetic practice. cárdenas thus describes its discursive and material terrain:

Building on the notion of "trans" from "transgender," I propose that transreal aesthetics cross the boundaries of reality created by a fragmentation of reality that occurred as a result of postmodern theory and emerging technologies. ${ }^{44}$

The psychic and physical nature of gender transition, which cárdenas herself underwent while theorizing the "transreal," informs the idea of multiplying and crossing realities as an embodied practice. Gender boundaries, just like the separation between "virtual" and "physical," are contested and blurred within a transreal perspective that makes use of digital interfaces such as videogames, VR, augmented realities, and other hacker strategies of technological disruption. 
Research indeed indicates that participation in cyberspace has a beneficial impact on the experience of gender transition, by enabling transgender users "to undergo meaningful experiences that are hard to attain in the offline world." 45 From a theoretical point of view, trans scholar Cáel Keegan has also argued that it is the sensed and actual experience of gender transition in trans* studies that differentiates it from women's and queer studies: "An alliance between women's studies and queer studies may thus value trans* studies for its ability to demonstrate gender as performative, but may struggle to hear its specifically gendered or materially embodied claims as real." ${ }^{46}$ A transreal aesthetics thus bases itself on trans studies' embodied knowledge and, at its digital intersections, on the potential of the virtual to contest, disrupt, and transform reality and matter.

From a transreal perspective, cárdenas's practice attempts to collapse the separation between virtual and physical through spatial and temporal crossings that give way to alternative and multiple notions of time and space. These alternatives are defined against heteronormative temporal linearity and involve radically inclusive acts of world-making. ${ }^{47}$ In $\mathrm{Sin} \mathrm{Sol} / \mathrm{No}$ Sun, the crossing of realities is manifested: spatially, through the use of augmented reality that allows users to visualize Aura and her digital environment within their own physical surroundings, and temporally, by being immersed in a speculative narrative of a past threatened with an impending ecological catastrophe.

\section{Sin Sol: Avatars of Ecological Resistance}

Sin Sol/No Sun is situated in an imaginary 2077, where the players partake in a process of archival excavation of memories and experiences that the AI Aura lived in 2019 (which more or less coincides to the actual lived present). ${ }^{48}$ The words that welcome the players at the beginning of the game reveal that what they see is her virtual body, which she coded at the time of the fires in order to find a new life beyond her presumably imminent death: "I- am here, to tell you how the sky died, how those who travelled across borders and built homes here could only run to the ocean, for fear of the cops at the shelters, how I coded my own body and soul..." These words encapsulate the present days' increase of wildfires and smoke storms; the impossibility for migrant and refugee communities to find a safe space within environmental catastrophes; the increase of police violence and border surveillance. As they are confronted with a narrative that corresponds to their present-time climate events, daily violence, and gender/racial oppressions, the players understand Aura's backed-up memories as their own lived experiences. With technology as a tool for digital survival, Aura goes on to recount her anxiety of preserving her memory across time:

Every day I upload my backups to the server / Occasionally I email copies of new writing to friends / I do this out of a sense of desperation / that I might die / that we all might die... that no one will remember that we had hope / for a future / where racism, transphobia and global warming / could be a forgotten dusty past memory.

The ability to see Aura's avatar and her dog forces the players to witness their physical death, thus confronting them with their present responsibility towards climate change and social justice. The game hence calls upon players to mourn the environmental collapse and to show solidarity with Aura: in spite of her physical departure, cárdenas's avatar is both a survivor and a political 
activist in a future world that, due to the extreme climate, may only be inhabitable to virtual creatures.

In a critical analysis of the concept of the avatar, cultural historian Uri McMillan observes its roots in pre-digital practices, including the spiritual connotations of avatars as deities embodied in human form. ${ }^{49}$ McMillan's book Embodied Avatars (2015) deploys the concept of the avatar to interpret the role of the body in Black feminist performance art in which artists explore alternate versions of the self and "transmute their simulated identities into transhistorical figurations." 50 McMillan writes:

I rerender "avatar" in the service of black performance art to gesture toward some of the oldest (and newest) forms of impersonation staged by black women and the conversion of these self-effacing performances into literary, visual, and digital remains. ${ }^{51}$

The performative manifestation of the avatar has a shape-shifting quality, which reveals the potential for traveling across time and representational forms. ${ }^{52}$ Though cárdenas's Aura may not be "embodied" in flesh, she is nevertheless one of the artist's collaborative virtual embodiments, performing across time and space. cárdenas describes Aura's 3D avatar as "a multiplicity, stitched together and performed by an algorithm": her face was modelled after Afro Latina Puertoriqueña actress MJ Rodriguez; her words come from micha cárdenas's own voice, who describes herself as translatina or trans woman of color; and her story is inspired by a 2017 chronicle of undocumented Mexican immigrants who tried to escape wildfires in California by running to the ocean. ${ }^{53}$ McMillan's avatar analysis focusses on the "performances of alterity" of real historical characters (such as Joice Heth and Ellen Craft) and of contemporary artists (such as Adrian Piper and Howardena Pindell). ${ }^{54}$ However, the author suggests that "embodied avatars" are not only performing through their physical bodies but are also able to speculatively traverse different realities in disembodied forms. ${ }^{55}$ Likewise, feminist theorist Elizabeth Grosz elaborates on the speculative dimension of the virtual, commenting that " $[\mathrm{t}] \mathrm{h}$ e virtual reality of computer space is fundamentally no different from the virtual reality of writing, reading, drawing, or even thinking." 56 The virtual was therefore close to human civilization even before the appearance of the digital, encapsulating the possibility of change and creative imagination:

The virtual is the space of emergence of the new, the unthought, the unrealized, which at every moment loads the presence of the present with supplementarity, redoubling a world through parallel universes, universes that might have been. ${ }^{57}$

As a trans Latina avatar of color, Aura gives shape, through her virtual presence and actions, to a speculative reality that disrupts the Western idea of progress and linear storyline. Aura embodies a new reality for the racialized human subject that parallels the speculative potential of what Tavia Nyong'o has named "afro-fabulation." Through the concept and practice of afro-fabulation, "black bodies that were objects of speculation" (as they have historically been the target of violence, exploitation, slavery, forced reproduction, or sterilization) can become "speculative bodies." ${ }^{\prime 5}$ Nyong'o affirms that this potential, which creates "the possibility of imagining humanity otherwise," comes from the very exceptions that blackness and queerness (and most importantly, I would add, transness) represent against the humanist standards: ${ }^{59}$ 
If we are "not yet" consistently accorded human status, if we remain an enigmatic shadow cast over the human project, then the shape of the humanity that we might envision would be wholly different from humanity as we know it today. ${ }^{60}$

At the same time, Nyong'o reminds us, we remain unable to know what a human in this speculative world "could be, do, or look like" - since we have yet to realize a world that is not anti-Black. ${ }^{61}$ However, I would argue that if afro-fabulation opens up the possibilities of imagining other forms of being human, through this lens we can also start to conceive ways to inhabit worlds that are not colonial or extractivist, and that account for an ecological non-human interdependence. $^{62}$ Being analogously aligned with a transreal space-time disruption, afrofabulation allows us to speculate worlds beyond the logics of capital and biological determinism: "[r]ather than emerging out of capitalist development or biological evolution, afro-fabulation 'anarranges' the developmental and linear timeline of history." ${ }^{\text {"I }}$ In the game, Aura comes out of another oxygen capsule emanating light blue mist. Her soft yet resolute voice resonates:

We failed / by allowing racial capitalism to be normal / by acting as if colonial violence, patriarchy and deadly national borders were tolerable daily situations / young people told us that we were creating climate crisis / but we kept going about our days / as if the world wasn't literally burning beneath us....

Understanding time beyond the reductive logic of capitalist profit or the small-scale dimension of a human lifetime is key to acknowledging the extent of human actions on a planetary level. By disrupting the linearity of time with the use of avatars and augmented reality, Sin Sol/No Sun allows players to tune in to the deep time of Earth and the polytemporality of all things. Challenging how categories of space and time have been historically constructed by a white, colonial, Western, heteronormative, and gender-binary deterministic discourse, the work of cárdenas - in dialogue with theorists like Haraway, Stone, McMillan, Grosz, and Nyong'odemonstrates the possibilities of formulating alternative histories that are radically ethical and poetic. The music becomes more intense. We keep on following Aura's dog across the virtu-real environments of a segment of California's forest, superimposed to our park (or garden, or wherever we are playing Sin Sol/No Sun from). As we reach the end of the game, having been moved (both psychically and literally) through Aura's mourning, another text appears next to her glitched body, calling us to join a digital insurrection:

If anyone is left who can hear this / any android goddess / any rebellious holograms / any sad, angry, dancing, traumatized but hopeful AI / REJECT YOUR PROGRAMMING / INTERRUPT ALGORITHMS OF DAILY RITUAL / THIS IS NOT A NORMAL RUNTIME ENVIRONMENT / we must end this so called order.

With Aura's final words, cárdenas once again reminds us to stop the simplistic ideas we have of space and time (i.e., the "daily ritual," "normal runtime environment," "order") and to subvert instead the algorithm that digital colonial capitalism has embedded in our lives. Aura's rebellion across multiple realities encourages the players and their avatars to engage critically with the ecology they are part of, and to refuse harmful habits or routines. Utilizing a transreal aesthetic and afro-fabulation, the game reminds the players that colonial, patriarchal, ableist, and sexist normalcy is perpetuated across multiple realities, and that this will inevitably contribute to the environmental breakdown. 
Sin Sol/No Sun ultimately reinforces the perceptual associations between virtual and real through the creation of affective interconnections between players and avatars, as well as providing the political and spiritual space for grief and hope. While reading, watching, and hearing Aura's poignant account of slow, inevitable death, the players are also mourning with her the incumbent environmental apocalypse. At the same time, Aura's avatar embodiment urges them-as Douglas Crimp enjoins us - to transform "mourning into militancy." ${ }^{64}$ Mourning, as Judith Butler also points out, holds a transformative relational potential, as it provides "a sense of political community... by bringing to the fore the relational ties that have implications for theorizing fundamental dependency and ethical responsibility." ${ }^{26}$ As players, while our political and ethical alliances are activated through the healing and transformative power of affect produced through Aura's virtual materialization, we also acknowledge how understanding and strategically employing digital technologies is integral for imagining and creating sustainable and livable worlds. The transreal aesthetics that cárdenas deploys - informed by both transgender materialism and Black feminist theory — can thus ignite an ontological shift in our understanding of reality.

The game is over... or is it? How do we exit if we've always been in it? A group of kids starts playing music louder than the game I am in. I close the app and walk back home, along the all too familiar footpath where, just a moment ago, a trans woman of color opened up her soul to me, sharing her story of despair and resistance.

Subject: Evacuated, expect a significant delay

Hello,

Thank you for your email. Due to the California wildfires and evacuation orders in Santa Cruz, I am away from home. I will reply to your email when I can attend to work again. I appreciate your patience.

Sincerely,

micha

I received this automatic reply in my inbox after emailing micha cárdenas at the end of August 2020, a few days after finalizing the very first draft of this essay. I checked micha's Twitter: there was a post from the day before. The sky was orange, and the sun looked red, as if a filter had been superimposed. But, of course, this was not the case, and micha was escaping from the wildfires just like Aura in the game.

I immediately felt a contradictory feeling of femme solidarity and guilt, as I once naively thought that the game's apocalyptic scenario was too extreme to take place just yet. The experience of playing Sin Sol/No Sun in the park near where I live in East London, and the writing of this text, immediately took on an even more tangible form. Aura's reality was indeed entangled with the lived experience of her author and the material ecological challenges that, together with many others, she has been living through, and fighting for, on a daily basis. 


\section{ENDNOTES}

1. The work premiered in 2018 at Henry Art Gallery in Seattle, Washington (US) as part of the Between Bodies exhibition. More on the project's webpage: micha cárdenas, "Sin Sol / No Sun," 2018, accessed August 10, 2020, https://michacardenas.sites.ucsc.edu/sin-sol-no-sun/.

2. micha cárdenas's work has been described as "a seminal milestone for artistic engagement in VR" and she is the co-author of The Transreal: Political Aesthetics of Crossing Realities (2012) and Trans Desire/Affective Cyborgs (2010). Her book Poetic Operations, which will be published in 2022, aims at analyzing and breaking through algorithms as a method of survival, from a trans of color poetics. Ecological concerns have been expressed in other of her digital works such as: Transborder Immigrant Tool (collaboratively devised in 2007 by Electronic Disturbance Theater 2.0/b.a.n.g. lab, of which micha cárdenas is part), a mobile phone application that served to guide individuals crossing the Mexico-US border towards water sources; and Redshift \& Portalmetal (2014), an online game set in a speculative future in which the protagonist (a trans woman of color) needs to escape the planet Earth's extreme toxic pollution. More on her website: micha cárdenas, "Home," last modified August 7, 2020, https://michacardenas.sites.ucsc.edu/ and Net Art Anthology, "Transborder Immigrant Tool," accessed October 6, 2020, https://anthology.rhizome.org/transborder-immigrant-tool.

3. Laura Paddison, "2019 Was the Year the World Burned," HuffPost US, December 27, 2019, accessed August 112020 https://www.huffingtonpost.co.uk/entry/wildfires-californiaamazon-indonesia-climate-change n 5dcd3f4ee4b0d43931d01baf.

4. I have borrowed the expression "traditionally marginalized subjects" from Kay Siebler, who uses the term "Traditionally Marginalized People" to indicate groups who have traditionally resided outside the dominant power structures of "white privilege." Kay Siebler, Learning Queer Identity in the Digital Age (London: Palgrave, 2016), 15.

5. Since 2016, the threat to the native lands of Standing Rock Sioux Tribe has sparked international solidarity with on-site camping and creative protests; Extinction Rebellion was born in the UK in Autumn 2018 and quickly spread globally. See: National Geographic Society Newsroom, "A Harmonious Resistance Creates Global Solidarity for Standing Rock," National Geographic, March 5, 2017, accessed August 10, 2020, https://blog.nationalgeographic.org/2017/03/05/a-harmonious-resistance-creates-globalsolidarity-for-standing-rock and XR. "Extinction Rebellion," accessed August 10, 2020 https://rebellion.global/about-us/.

6. Aleksandra Wisniewska, "What Happens to Your Old Laptop? The Growing Problem of eWaste," Financial Times, January 10, 2020, accessed August 7, 2020, https://www.ft.com/content/26e1aa74-2261-11ea-92da-f0c92e957a96.

7. Evelyn Wan, "Labour, Mining, Dispossession: On the Performance of Earth and the Necropolitics of Digital Culture," International Journal of Performance Arts and Digital Media 15, no. 3 (2019): 253.

8. An article from 2018 by the scientific journal Nature informs how "the information and communications technology (ICT) ecosystem as a whole-under a sweeping definition that encompasses personal digital devices, mobile-phone networks and televisions - accounts for more than $2 \%$ of global emissions. That puts ICT's carbon footprint on a par with the aviation industry's emissions from fuel." Nicola Jones, "How to Stop Data Centres from Gobbling up the World's Electricity," Nature, September 12, 2018, accessed August 7, 2020, https://www.nature.com/articles/d41586-018-06610-y; additionally: Beth Whitehead et al., 
"Assessing the Environmental Impact of Data Centres Part 1: Background, Energy Use and Metrics," Building and Environment 82 (2014): 151.

9. Joy Buolamwini, "We Must Fight Face Surveillance to Protect Black Lives: An Urgent Letter from the Algorithmic Justice League," OneZero, June 3, 2020, accessed October 4, 2020, https://onezero.medium.com/we-must-fight-face-surveillance-to-protect-black-lives5ffcd0b4c28a.

10. Michael Kwet, "Digital Colonialism: US Empire and the New Imperialism in the Global South," Race \& Class 60, no. 4 (2019): 1.

11. The coining of the term "virtu-real" in the early 1990s points to the increasing slippage between virtual and "real" space. In 1993 artist Jeffrey Schulz stated: "It is no longer possible to speak only of real (physical) space; nor is it the case that virtual space has colonized real space (the contemporary landscape is not, and never will be, total virtual reality). Rather, the two categories of virtual and real space have collapsed into one another, creating a virtu-real space that on the surface seems like real space but is significantly different from it, especially in terms of the social relations that it produces." Even in this space - the author observes racial minorities have continued to be kept at the margins, and the common language has remained "symbolically and politically binary." Jeffrey Schulz, "Virtu-Real Space: Information Technologies and the Politics of Consciousness," Leonardo 26, no. 5 (1993): 439.

12. Cornelia Sollfrank (b. 1960, Germany) is a net art pioneer, experimenting with alternative models for authorship and collaborative structures; she initiated the cyberfeminist network Old Boys Network (1997-2001) and co-organized three international Cyberfeminism conferences (in 1997, 1999 and 2001). Shu Lea Cheang (b. 1954, Taiwan) works with a variety of art mediums and film formats to redefine gender, sexuality, geo-politics and economic structures, often through net-based works and participatory installations; she is known for the web-art work BRANDON (1998-1999) and her sci-fi cyberpunk (I.K.U., 2000), among others. For more information: Monokshop, "Cornelia Sollfrank," October 12 , 2019, accessed October 4, 2020, https://monoskop.org/Cornelia Sollfrank and Universes in Universe, "Shu Lea Cheang: Artist Representing Taiwan at the 58th Venice Biennale," 2019, accessed October 4, 2020, https://universes .art/en/venice-biennale/2019/taiwan/shu-leacheang.

13. Joanna Walsh, "Post-Cyber Feminist International," Frieze, November 28, 2017, accessed August 10, 2020, https://frieze.com/article/post-cyber-feminist-international-2017.

14. Maria Fernandez and Faith Wilding, "Situating Cyberfeminisms," in Domain Errors: Cyberfeminist Practices!, A subRosa Project, ed. Maria Fernandez, Faith Wilding and Michelle M. Wright (New York: Autonomedia, 2002), 22.

15. "A Cyborg Manifesto: Science, Technology, and Socialist-Feminism in the Late Twentieth Century" was first published in Socialist Review and later included as a chapter of Haraway's book Simians, Cyborgs, and Women in 1991. Donna Haraway, "Acknowledgements," in Simians, Cyborgs, and Women: The Reinvention of Nature (New York: Routledge, 1991), x.

16. Donna Haraway, "A Cyborg Manifesto," in Simians, Cyborgs, and Women, 150, 155.

17. Ibid, 155.

18. Art historian Griselda Pollock has theorized the canon as "a discursive formation which constitutes the objects/texts it selects as the products of artistic mastery and thereby, contributes to the legitimation of white masculinity's exclusive identification with creativity and Culture." Griselda Pollock, Differencing the Canon: Feminist Desire and the Writing of Art's Histories (London and New York: Routledge, 1999), 9. 
19. VNS Matrix, "The Cyberfeminist Manifesto for the 21st Century," 1991, accessed August 4, 2020 https://vnsmatrix.net/projects/the-cyberfeminist-manifesto-for-the-21st-century.

20. Fernandez and Wilding, "Situating Cyberfeminisms," 22-23.

21. Donald Morton, "Birth of the Cyberqueer," PMLA, 110, no. 3 (1995): 369.

22. Ibid, 375.

23. Nina Wakeford, "Cyberqueer," in The Cybercultures Reader, ed. David Bell and Barbara M. Kennedy (London: Routledge, 2000), 410. This essay was originally published in 1997.

24. Ibid, 412.

25. Ibid, 408, 404.

26. Ibid, 413.

27. Lisa Nakamura, Digitizing Race: Visual Cultures of the Internet (Minneapolis and London: University of Minnesota Press, 2007), 4.

28. Ibid, 4-5.

29. Cyberfeminism aimed to attract "particularly women from diverse backgrounds and orientations, particularly young women unwilling to call themselves feminists;" in 1997, during the "First Cyberfeminist International" (which took place at Documenta X in Kassel), it embraced a definition by negation, comprised of "100 anti-theses," such as: cyberfeminism is not ideology; is not an ism; is not anti-male; is not a theory. Fernandez and Wilding, "Situating Cyberfeminisms," 23,18. To read the anti-theses: obn, "100 Anti-Theses," accessed August 4, 2020 https://www.obn.org/cfundef/100antitheses.html.

30. Ramón Reichert and Annika Richterich, "Introduction: Digital Materialism," in Digital Culture and Society 1, no. 1 (2015): 12.

31. Ibid, 12, 7-8.

32. Ibid, 8 .

33. Historically, the digital has proved to be an inhospitable technology for subjects marginalized for their class, gender, or race. Recent statistics continue to showcase a global disproportion of women having technological literacy, especially in Africa, South Asia, and other developing parts of the world. On the other hand, women and other traditionally marginalized individuals have used digital technologies to advance social justice projects worldwide, for example, by using internet's visual interfaces to combat illiteracy. As demonstrated across movements joined under the hashtags \#BlackLivesMatter, \#MeToo, or \#NiUnaMenos, traditionally marginalized people have recently also taken advantage of digital technologies, creating transnational political mobilization, art and community beyond physical and social divides. See: OECD, Bridging the Digital Gender Divide: Include, Upskill, Innovate (Paris: OECD, 2018), 13; Danielle Robertson and Mena Ayazi, "How Women Are Using Technology to Advance Gender Equality and Peace," United States Institute of Peace, July 15, 2019, accessed August 4, 2020, https://www.usip.org/publications/2019/07/how-womenare-using-technology-advance-gender-equality-and-peace; and Lisa Nakamura, Digitizing Race, 88.

34. I use "trans" as an umbrella term, to recognize a variety of gender nonconforming embodiments, expressions, and identities. In this description I align myself with the definition provided by cárdenas and Chen: "We use the term trans to recognize multiple embodiments, expressions, and identities of gender nonconformity and variance that surpass - and potentially decolonize - racially constituted white, binary gender/sex, while maintaining links to transgender's resistant repurposing of Western psycho-medical science and to trans*'s broad inclusiveness based on the algorithmic command to "trans everything." micha 
cárdenas and Jian Neo Chen, “Times to Come: Materializing Trans Times," TSQ 6, no.4 (2019): 472.

35. In the very first line of the chapter "A Cyborg Manifesto" Haraway states that her writing constitutes "an effort to build an ironic political myth faithful to feminism, socialism, and materialism," (ibid, 149).

36. She states: "'Women of colour' are the preferred labour force for the science-based industries... Young Korean women hired in the sex industry and in electronics assembly are recruited from high schools, educated for the integrated circuit. Literacy, especially in English, distinguishes the 'cheap' female labour so attractive to the multinationals" (ibid, 174). Haraway's analysis of "homework economy" in the Silicon Valley also shows how "work is both literally female and feminized, whether performed by men or women. To be feminized means to be made extremely vulnerable; able to be disassembled, reassembled, exploited as a reserve labour force..." (ibid, 166).

37. Haraway borrows the image of women in the "integrated circuit" (which technically refers to a microchip) from Rachel Grossman (1980) (ibid, 165).

38. 38 Sandy Stone, “The Empire Strikes Back: A Posttranssexual Manifesto," ed. Susan Stryker and Stephen Whittle, The Transgender Studies Reader (London and New York: Routledge, 2006), 230-231.

39. Ibid, 232.

40. Ibid.

41. In 1955 Sandy Stone worked at Bell Labs company for the research and development of communication technologies, audited the classes of early cyberneticists (already called "hackers") at MIT (Massachusetts Institute of Technology), did medical research, and ended up becoming a recording engineer, before starting her gender transition and her $\mathrm{Ph}$. D. at the University of Santa Cruz. Susan Stryker, "Another Dream of Common Language: An Interview with Sandy Stone,” TSQ: Transgender Studies Quarterly 3, no. 1-2 (2016): 294295,300 .

42. Allucquère Rosanne Stone, The War of Desire and Technology at the Close of the Mechanical Age (Cambridge, MA: The MIT Press, 1995), 180-183.

43. Astrid Schwarz and Kurt Jax, "Etymology and Original Sources of the Term 'Ecology,"' in Ecology Revisited, ed. Astrid Schwarz and Kurt Jax (Dordrecht: Springer, 2011), 145.

44. micha cárdenas, "Introduction," ed. Zach Blas and Wolfgang Schirmacher, The Transreal: Political Aesthetics of Crossing Realities (New York: Atropos Press, 2011), 23.

45. Avi Marciano, "Living the VirtuReal: Negotiating Transgender Identity in Cyberspace," Journal of Computer-Mediated Communication 19 (2014): 834.

46. Cáel M. Keegan, “Getting Disciplined: What's Trans* about Queer Studies Now?,' Journal of Homosexuality (2018): 9. Keegan uses "trans*" to indicate "a broader formation including the theories, cultural productions, political imaginaries, bodies, and material praxes historically created by trans populations" (Ibid, 12).

47. cárdenas expands on the notion of queer time and space elaborated by Jack Halberstam. cárdenas, "Introduction," 23-24, 26. For Halberstam's reference see: In a Queer Time and Place: Transgender Bodies, Subcultural Lives (New York and London: New York University Press, 2005), 1.

48. I have deduced these dates from the caption of one of the texts, which reads:

"...///transmission received 2077 from errant navigational AI. Aura2019."

49. “'Avatar,' a term from Hindu mythology, is derived from the Sanskrit word avatara. Combining the prefix ava ('down') with the base of tara ('a passing over'), its translation of 
'downcoming' denotes the descent of a deity to earth in order to be reincarnated in a human form. Entering the English language at the end of the eighteenth century, its meanings grew less spiritual and more rhetorical and allegorical. In 1985, the word 'avatar' was first applied to virtual persona." Uri McMillan, Embodied Avatars: Genealogies of Black Feminist Art and Performance (New York and London: New York University Press, 2015), 11.

50. Ibid, 12.

51. Ibid.

52. Ibid, 13.

53. micha cárdenas, email to author, August 4, 2021. See: Amy Goodman et al., "Fearing Deportation, Immigrants Fleeing California Wildfires Avoid Shelters \& Face Homelessness," Democracy Now!, October 20, 2017, accessed 5 August 2021, https://www.democracynow.org/2017/10/20/immigrants fleeing california wildfires find $\mathrm{n}$ $\underline{\mathrm{O}}$

54. McMillan, Embodied Avatars, 12.

55. Ibid, 13

56. Elizabeth Grosz, Architecture from the Outside: Essays on Virtual and Real Space (Cambridge, MA and London: The MIT Press, 2001), 79.

57. Ibid, 78 .

58. Tavia Nyong'o, Afro-Fabulations: The Queer Drama of Black Life (New York: New York University Press, 2019), 25.

59. Ibid.

60. Ibid.

61. Ibid, 26.

62. In an interview, cárdenas herself states the importance of trans-species connection and survival: "The main question of the game is to ask how we can care for all people and all species, and perhaps even care about beings we might consider virtual, which will be necessary if we're all going to survive climate change." Allan Gardner, "MICHA CÁRDENAS, Algorithms and Poetics of Trans People of Colour," CLOT, March 18, 2019, accessed 11 August 2020, https://www.clotmag.com/interviews/micha-cardenas.

63. Ibid, 25-26.

64. Douglas Crimp, “Mourning and Militancy,” October 51 (1989): 9.

65. Judith Butler, Precarious Life: The Powers of Mourning and Violence (London and New York: Verso, 2004), 21-22.

\section{REFERENCES}

Blas, Zach and Schirmacher, Wolfgang, eds. The Transreal: Political Aesthetics of Crossing Realities. New York: Atropos Press, 2011.

Buolamwini, Joy. "We Must Fight Face Surveillance to Protect Black Lives: An Urgent Letter from the Algorithmic Justice League," OneZero, June 3, 2020, accessed October 4, 2020 , https://onezero.medium.com/we-must-fight-face-surveillance-to-protect-black-lives5ffcd0b4c28a. 
Butler, Judith. Precarious Life: The Powers of Mourning and Violence. London and New York: Verso, 2004.

cárdenas, micha. "Home," Last modified August 7, 2020. https://michacardenas.sites.ucsc.edu/.

cárdenas, micha. "Sin Sol / No Sun," 2018, accessed August 10, 2020,

https://michacardenas.sites.ucsc.edu/sin-sol-no-sun/.

cárdenas, micha and Chen, Jian Neo. "Times to Come: Materializing Trans Times," TSQ 6, no.4 (2019): 472-480.

Crimp, Douglas. "Mourning and Militancy," October 51 (1989): 3-18.

Fernandez, Maria and Wilding, Faith. "Situating Cyberfeminisms," in Domain Errors:

Cyberfeminist Practices!, A subRosa project, edited by Maria Fernandez, Faith Wilding and

Michelle M. Wright, 17-28. New York: Autonomedia, 2002.

Gardner, Allan. "MICHA CÁRDENAS, Algorithms and Poetics of Trans People of Colour," CLOT, March 18, 2019, accessed August 11, 2020, https://www.clotmag.com/interviews/michacardenas.

Goodman, Amy, De La Cruz, Alegría and Hernandez, Juan, "Fearing Deportation, Immigrants Fleeing California Wildfires Avoid Shelters \& Face Homelessness," Democracy Now!, October 20, 2017, accessed 5 August 2021, https://www.democracynow.org/2017/10/20/immigrants fleeing california wildfires find no.

Grosz, Elizabeth. Architecture from the Outside: Essays on Virtual and Real Space. Cambridge, MA and London: The MIT Press, 2001.

Halberstam, Jack. In a Queer Time and Place: Transgender Bodies, Subcultural Lives. New York and London: New York University Press, 2005.

Haraway, Donna. Simians, Cyborgs, and Women: The Reinvention of Nature. New York:

Routledge, 1991.

Jones, Nicola. "How to Stop Data Centres from Gobbling Up the World's Electricity," Nature, September 12, 2018, accessed August 7, 2020, https://www.nature.com/articles/d41586-01806610-y.

Keegan, Cáel M. “Getting Disciplined: What's Trans* About Queer Studies Now?” Journal of Homosexuality (2018): 1-14.

Kwet, Michael. "Digital Colonialism: US Empire and the New Imperialism in the Global South," Race \& Class 60, no. 4 (2019): 1-24.

Marciano, Avi. "Living the VirtuReal: Negotiating Transgender Identity in Cyberspace," Journal of Computer-Mediated Communication 19 (2014): 824-838. 
McMillan, Uri. Embodied Avatars: Genealogies of Black Feminist Art and Performance. New York and London: New York University Press, 2015.

Monoskop. “Cornelia Sollfrank,” October 12, 2019, accessed October 4, 2020, https://monoskop.org/Cornelia Sollfrank

Morton, Donald. "Birth of the Cyberqueer," PMLA, 110, no. 3 (1995): 369-381.

Nakamura, Lisa. Digitizing Race: Visual Cultures of the Internet. Minneapolis and London: University of Minnesota Press, 2007.

National Geographic Society Newsroom. "A Harmonious Resistance Creates Global Solidarity for Standing Rock," National Geographic, March 5, 2017, accessed August 10, 2020, https://blog.nationalgeographic.org/2017/03/05/a-harmonious-resistance-creates-globalsolidarity-for-standing-rock.

Net Art Anthology. “Transborder Immigrant Tool,” accessed October 6, 2020, https://anthology.rhizome.org/transborder-immigrant-tool.

Nyong'o, Tavia. Afro-Fabulations: The Queer Drama of Black Life. New York: New York University Press, 2019.

obn. "100 Anti-Theses," accessed August 4, 2020.

https://www.obn.org/cfundef/100antitheses.html.

OECD. Bridging the Digital Gender Divide: Include, Upskill, Innovate. Paris: OECD, 2018, accessed August 4, 2020, http://www.oecd.org/internet/bridging-the-digital-gender-divide.pdf.

Paddison, Laura. "2019 Was the Year the World Burned," HuffPost US, December 27, 2019, accessed August 11, 2020, https://www.huffingtonpost.co.uk/entry/wildfires-california-amazonindonesia-climate-change n 5 dcd3f4ee4b0d43931d01baf.

Pollock, Griselda. Differencing the Canon: Feminist Desire and the Writing of Art's Histories. London and New York: Routledge, 1999.

Reichert, Ramón and Richterich, Annika. "Introduction: Digital Materialism," in Digital Culture and Society 1, no. 1 (2015): 5-17.

Robertson, Danielle and Ayazi, Mena. "How Women Are Using Technology to Advance Gender Equality and Peace," United States Institute of Peace, July 15, 2019, accessed August 4, 2020, https://www.usip.org/publications/2019/07/how-women-are-using-technology-advance-genderequality-and-peace.

Schulz, Jeffrey. "Virtu-Real Space: Information Technologies and the Politics of Consciousness," Leonardo 26, no. 5 (1993): 437-444. 
Schwarz, Astrid and Jax, Kurt. "Etymology and Original Sources of the Term 'Ecology," in Ecology Revisited, edited by Astrid Schwarz and Kurt Jax, 145-147. Dordrecht: Springer, 2011.

Siebler, Kay. Learning Queer Identity in the Digital Age. London: Palgrave, 2016.

Stone, Allucquère Rosanne. The War of Desire and Technology at the Close of the Mechanical Age. Cambridge, MA: The MIT Press, 1995.

Stone, Sandy. "The Empire Strikes Back: A Posttranssexual Manifesto," in The Transgender Studies Reader, edited by Susan Stryker and Stephen Whittle, 221-235. London and New York: Routledge, 2006.

Stryker, Susan. "Another Dream of Common Language: An Interview with Sandy Stone," TSQ: Transgender Studies Quarterly 3, no. 1-2 (2016): 294-305.

Universes in Universe. "Shu Lea Cheang: Artist Representing Taiwan at the 58th Venice Biennale," 2019, accessed October 4, 2020, https://universes.art/en/venicebiennale/2019/taiwan/shu-lea-cheang.

VNS Matrix. "The Cyberfeminist Manifesto for the $21^{\text {st }}$ Century,” 1991, accessed August 4, 2020, https://vnsmatrix.net/projects/the-cyberfeminist-manifesto-for-the-21st-century.

Wakeford, Nina. "Cyberqueer," in The Cybercultures Reader, edited by David Bell and Barbara M. Kennedy, 403-415. London: Routledge, 2000.

Walsh, Joanna. "Post-Cyber Feminist International," Frieze, November 28, 2017, accessed August 10, 2020, https://frieze.com/article/post-cyber-feminist-international-2017.

Wan, Evelyn. "Labour, Mining, Dispossession: On the Performance of Earth and the Necropolitics of Digital Culture," International Journal of Performance Arts and Digital Media 15, no. 3 (2019): 249-263.

Whitehead, Beth, Andrews, Deborah, Shah, Amip, and Maidment, Graeme. "Assessing the Environmental Impact of Data Centres Part 1: Background, Energy Use and Metrics," Building and Environment 82 (2014): 151-159.

Wisniewska, Aleksandra. "What Happens to Your Old Laptop? The Growing Problem of eWaste," Financial Times, January 10, 2020, accessed August 7, 2020, https://www.ft.com/content/26e1 aa74-2261-11ea-92da-f0c92e957a96.

XR. “Extinction Rebellion.” Accessed August 10, 2020 https://rebellion.global/about-us/. 


\section{AUTHOR BIO}

Giulia Casalini is an independent curator-artist based in London, and currently a PhD candidate at Roehampton university (Techne-funded, 2019-2023). Her research analyzes artists and collectives from across the globe whose live art practices have been informed by queer-feminist politics and aesthetics beyond the Anglo-American canons. She is the co-founder and artistic director of the non-profit arts organization Arts Feminism Queer (CUNTemporary, 2012-2020). Her curatorial practice engages with queer-feminist methodologies to create multidisciplinary exhibitions and events across institutional and alternative spaces. Selected projects include: EcoFutures (multi-venue festival, London, 2019); Still Burning (Varbergs Konsthalle, Varberg, 2019); Transitional States (touring at Project Space Plus, Lincoln; Peltz Gallery, London; Labs Gallery, Bologna; CCCB, Barcelona, 2017-2018); Transformer (Richard Saltoun Gallery, London, 2014). 